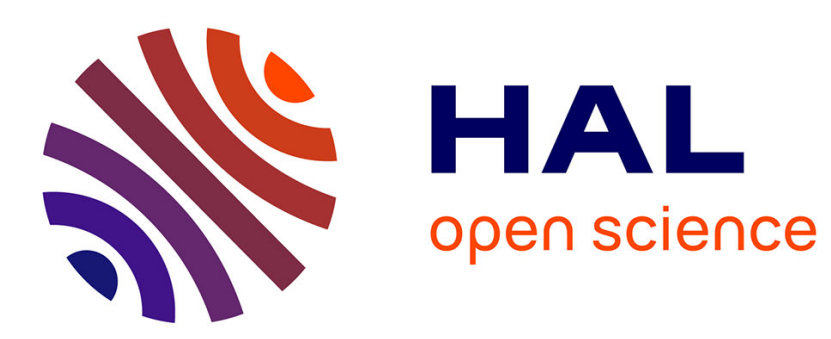

\title{
When People Would Rather Switch Than Fight: Out-Group Favoritism Among Temporary Employees \\ Courtney D. von Hippel
}

\section{To cite this version:}

Courtney D. von Hippel. When People Would Rather Switch Than Fight: Out-Group Favoritism Among Temporary Employees. Group Processes and Intergroup Relations, 2006, 9 (4), pp.533-546. 10.1177/1368430206067556 . hal-00571628

\section{HAL Id: hal-00571628 \\ https://hal.science/hal-00571628}

Submitted on 1 Mar 2011

HAL is a multi-disciplinary open access archive for the deposit and dissemination of scientific research documents, whether they are published or not. The documents may come from teaching and research institutions in France or abroad, or from public or private research centers.
L'archive ouverte pluridisciplinaire HAL, est destinée au dépôt et à la diffusion de documents scientifiques de niveau recherche, publiés ou non, émanant des établissements d'enseignement et de recherche français ou étrangers, des laboratoires publics ou privés. 


\title{
When People Would Rather Switch Than Fight: Out-Group Favoritism Among Temporary Employees
}

\author{
Courtney D. von Hippel \\ University of New South Wales
}

\begin{abstract}
This article relies on social identity theory to examine the intergroup attitudes held by temporary and permanent employees toward each other. Because temporary employees represent a low-status group with permeable boundaries, temporary employees were expected to show an out-group bias in favor of permanent employees. Survey data from 161 temporary and permanent employees revealed this predicted out-group favoritism on the part of the temporary employees on both implicit and explicit measures of intergroup bias. In contrast, the high-status, permanent employee group displayed typical in-group favoritism on both measures. Implications of these results for workplace relations are discussed.
\end{abstract}

KEYWORDS out-group favoritism, social identity theory, temporary employees, workplace

KAREN has been working at a company for six weeks. Although she works the same hours as her coworkers, she earns less money than other employees doing the same work and has fewer fringe benefits (e.g. no paid vacation days and limited health and retirement benefits). Few people at the company take the time to speak to Karen, and many do not know her name, as Karen was never issued a nametag. When there is a birthday or some other celebration in the staff room, Karen is not invited. In short, Karen feels alienated in her current work environment. Like a growing number of workers, Karen is a temporary employee. She works for a temporary agency and has been assigned to the company by her temporary agency. Similar stories occur in work sites all over America every day (Rogers, 1995). As one temporary employee put it: 'I think since they don't see you as being permanent they sort of dismiss you as being expendable, like you're not worth it' (quoted in Rogers, 1995).

Temporary work has been described as a phenomenon that may reshape business and

\section{Author's note}

Address correspondence to Courtney von Hippel, School of Psychology, University of New South Wales, Sydney, Australia 2052 [email: c.vonhippel@unsw.edu.au] 
personal lives in the near future by replacing full-time employment (Allerton, 1996). The temporary help industry has experienced tremendous growth with few signs of slowing down (Tyler, 2004). But despite the recent surge in temporary employment, there exists only limited research on the temporary employee population. The absence of systematic research on this issue is probably best explained by the relative recency of the phenomenon. The present research attempts to address this gap by examining temporary and permanent employees drawing on the perspective of social identity theory (SIT; Tajfel, 1978; Tajfel \& Turner, 1979). As such, the goal of this research was to assess the implicit and explicit intergroup attitudes held by temporary and permanent employees toward their coworkers.

\section{Social identity theory}

SIT posits that people evaluate members of their own group (in-group) more favorably than members of other groups (out-groups). In-groups can be composed of people who share any of a variety of traits or characteristics, such as being of the same religious affiliation, the same gender, the same hometown, etc., while out-groups consist of people who do not share those characteristics. Consequently, people have multiple in-groups and out-groups, and the same person can be part of either the in-group or out-group depending on the circumstances and context. In-group bias refers to the differential favoritism that people exhibit toward their own group compared to a relevant out-group. This in-group preference emerges in evaluations of performance, behavior, and personality, and in disbursement of rewards or punishment for performance (Brewer, 1979). In addition, it is not necessary for a person to have a strong in-group affiliation to exhibit an in-group bias. Even when group membership is based on seemingly trivial categories, like individuals' under- or overestimation of dots presented on a screen (i.e. minimal groups), researchers have found in-group biases (Tajfel \& Turner, 1986). The research evidence is compelling; in both natural and minimal groups individuals allocate more rewards to their in-group, shelter their in-group from punishment, and interpret in-group behaviors more favorably than identical out-group behaviors (e.g. Brewer \& Brown, 1998).

Tajfel (1978) explained the tendency for people to favor others who have been categorized into the same group as driven by a need for positive social identity. Because social identification is important to our self-concept, and people strive for positive self-concepts, people are motivated to evaluate their ingroups more positively than their out-groups (Tajfel \& Turner, 1986). If group membership provides people with a positive sense of self, the question then arises regarding what happens when the group is low status. Does low status group membership confront people with threats to their social identity? According to SIT, members of low status groups will be motivated to adopt a number of strategies to achieve a positive social identity, depending on a variety of socio-structural variables (i.e. stability of status, legitimacy of status, and permeability of group boundaries).

\section{Socio-structural variables}

Research on SIT and status differences between groups has revealed seemingly inconsistent findings. Low status groups sometimes show stronger in-group favoritism than their high status counterparts (e.g. Mummendey et al., 1992; Otten, Mummendey, \& Blanz, 1996), but other times show a bias in favor of the out-group, termed out-group favoritism (Boldry \& Kashy, 1999; Sachdev \& Bourhis, 1987). For example, Otten and her colleagues (1996) found that both high and low status groups favored their own group in the allocation of rewards, but in Sachdev and Bourhis' (1987) research, the lowstatus group favored the out-group on ratings relevant to the status differential.

One reason for these inconsistent findings is that there appear to be important moderators of when low status is likely to lead to group defensiveness versus out-group favoritism (Bettencourt, Dorr, Charlton, \& Hume, 2001). 
These moderators are the socio-structural variables of status stability, status legitimacy, and group permeability. Tajfel and Turner (1979, 1986) defined status stability as the extent to which the group's status as a whole can change, legitimacy of status as the extent to which group member's accept the status differential as legitimate, and permeability as the extent to which group members can leave their group to join another group. These three variables have been shown to moderate the relationship between group status and in-group favoritism (Bettencourt et al., 2001).

When participants perceive the status structure to be unstable, low status groups exhibit typical in-group favoritism (Turner \& Brown, 1978). Under these circumstances the low status group can persist and hope to switch their relative position with the high status group. Similarly, when the status differential is seen as illegitimate the low status group tends to show equivalent in-group favoritism as the high status groups. It should be noted that in the social identity literature, little research exists that examines stability and legitimacy independently (see Bettencourt et al., 2001). Rejection of the system is most likely when there is an unstable status structure coupled with perceived illegitimacy of the status structure (Tajfel, 1982). Under such conditions the low status group members are most likely to adopt a competitive strategy to achieve a positive social identity, and thus show the typical in-group favoritism.

Permeability also influences group member's responses to differences in status. If group boundaries are permeable, members of the low status group should adopt strategies that enhance individual upward mobility (Ellemers, van Knippenberg, de Vries, \& Wilke, 1988; Tajfel \& Turner, 1979, 1986). That is, low status group members should attempt to leave their group and join the high-status group. After all, why continue to support your low-status group in the face of detractors when it is possible to join the high status group? It is under these circumstances that low-status groups should be most likely to favor the out-group. Indeed, an upward mobility strategy is most likely when the group boundaries are permeable and the status structure is perceived as legitimate and stable (Ellemers, van Knippenberg, \& Wilke, 1990).

Although these variables are often manipulated in the laboratory, not surprisingly natural groups also differ in their status legitimacy, stability, and permeability. For example, women are typically thought to be of lower status than men, because they have less social power (Bem, 1994; Sekaquaptewa \& Espinoza, 2004; Stewart, Vassar, Sanchez, \& Susannah, 2000). In this case the group boundaries are impermeable, the status structure is relatively stable, and the status legitimacy is commonly perceived as illegitimate in most technological societies. As such, we would expect women to show typical in-group favoritism, and research supports this line of reasoning (Lindeman \& Sundvik, 1995).

\section{Temporary workers and the socio-structural variables}

Knowing how temporary workers differ on these socio-structural variables can allow predictions to be made regarding their intergroup attitudes, based on SIT. Temporary employees are perceived to have lower status than permanent employees (Boroughs, 1994; Davidson, 1999; Feldman, Doerpinghaus, \& Turnley, 1994) and often complain that they are treated as second-class citizens (Rogers, 1995). It seems that their low status engenders poor treatment from their permanent coworkers, with temporary workers complaining that their colleagues ignore them or take advantage of them (Rogers, 1995; see also, Wheeler \& Buckley, 2001). Indeed, this lower perceived status of temporary employees can even impact their permanent coworkers, who suffer a less positive social identity and lowered self-esteem when they work in groups that have a high proportion of temporary employees (Chattopadhyay \& George, 2001). Temporary employees, in contrast, seemed to gain prestige through association with their permanent coworkers. In combination with the fact that temporary workers are thought to be employed in positions with less informational and technical 
complexity (Davis-Blake \& Uzzi, 1993), these findings suggest that people regard the low status of temporary employees as legitimate.

Given the widespread perception that temporary employees are legitimately of lower status than permanent employees, it is not surprising that many temporary employees hope to gain a regular job within the organization at which they are placed (Bourhis \& Wils, 2001; Feldman, Doerpinghaus, \& Turnley, 1994, 1995; C. von Hippel, Mangum, Greenberger, Heneman, \& Skoglind, 1997). A recent study indicates that nearly three quarters of temporary workers are hoping to find permanent positions through their temporary placements (Tyler, 2004). Indeed, many temporary employees do gain regular jobs through their temporary placements (C. von Hippel et al., 1997), a phenomenon referred to as 'temp to perm'. Thus, it seems clear that the boundaries between temporary and permanent employees are permeable.

In sum, temporary employees form a naturally occurring low status group in which membership is permeable, and in which the low status is widely perceived as legitimate. As such, temporary employees provide a natural group that allows an assessment of the prediction from SIT that such groups should favor their out-group. The goal of the current research is to test this possibility.

\section{Measuring bias}

There are a variety of ways to assess favoritism (e.g. trait ratings, allocation matrixes), but most of these methods rely on explicit ratings of bias. Because people may be unwilling to admit that they favor their in-group (or out-group) under certain circumstances (Franco \& Maass, 1996), an implicit measure of bias can be useful for circumventing the 'unwillingness' problem associated with self-report. With implicit measures, social desirability concerns are less relevant because people are typically unaware that their attitudes are being measured. Thus, implicit measurement techniques enable researchers to measure attitudes without directly asking about them.
Of the many implicit measures available, this study relied on the Linguistic Intergroup Bias (LIB; Maass, Salvi, Arcuri, \& Semin, 1989) as an implicit measure of group favoritism. The LIB refers to the tendency to describe behavior abstractly when referring to negative out-group or positive in-group behavior and concretely when referring to negative in-group and positive out-group behavior. For example, if an out-group member were seen striking someone, people would describe the event with abstract terms (e.g. 'Brad is violent'), whereas this same behavior by an in-group member would be described in more concrete terms (e.g. 'Brad hit someone'). In this way, people only communicate inferences about a person's underlying characteristics regarding a negative behavior when it is performed by an out-group member. The opposite pattern emerges with positive behaviors. For example, if an in-group member were seen directing a blind person across the street, the behavior would be described abstractly (e.g. 'Brad is helpful') whereas this same behavior by an out-group member would be described in concrete terms (e.g, 'Brad helped the blind person cross the street') (Maass, Milesi, Zabbini, \& Stahlberg, 1995). Thus, people only communicate inferences about a person's underlying characteristics regarding a positive behavior when it is performed by an in-group member.

Maass and her colleagues (1995) have examined the psychological mechanism underlying the LIB and have found that differential expectancies of in-group and out-group behavior are at least partially responsible. Behavior consistent with prior beliefs or preferences is described abstractly, whereas behavior inconsistent with prior beliefs or preferences is described concretely. The LIB appears to be an implicit measure of intergroup bias, as people show the LIB toward out-group members even in situations where social desirability precludes them from showing in-group biases in their explicit evaluations (Franco \& Maass, 1996; W. von Hippel, Sekaquaptewa, \& Vargas, 1997).

When assessing the LIB, bias can be measured by having people indicate how well statements of varying levels of abstraction 
describe a scenario they have encountered. According to Semin and Fiedler's (1988) Linguistic Category Model, the most concrete statements refer to objective descriptions of observable behaviors that have a clear beginning and end, and the most abstract statements describe highly abstract personal dispositions. To the degree that people feel that concrete statements but not abstract statements provide a good description of a scenario, they are demonstrating that they are unwilling to communicate an inference about the person. In contrast, if people feel that abstract statements are a good descriptor of the scenario, then they are demonstrating a willingness to communicate an inference about the person. Research suggests that when people engage in the LIB they rely on stereotypes to evaluate others, they communicate those stereotypes, and they view the information they have encountered as consistent with those stereotypes (W. von Hippel et al., 1997; Wigboldus, Semin, \& Spears, 2000).

\section{Hypotheses}

Following the principles of SIT and the findings of Ellemers et al. (1988, 1990), it is expected that like other high status groups, permanent employees will show in-group favoritism. Temporary employees, in contrast, are members of a low status group whose status is perceived as legitimate and stable, yet the boundaries to the high status group are permeable. Thus, according to SIT, temporary workers are unlikely to 'fight' for their group, but rather should exhibit out-group favoritism. This prediction also follows from system justification theory (Jost \& Banaji, 1994), according to which lower status groups legitimize the current social arrangements despite the fact that those arrangements are often not in the group's best interest (see Jost, Banaji, \& Nosek, 2004, for a review of system justification and how it differs from SIT).

It is unclear, however, whether temporary workers will show out-group favoritism to the same degree that permanent workers show ingroup favoritism. A recent meta-analysis demonstrated that when boundaries are permeable, high status groups show greater bias than their low status counterparts (Bettencourt, et al, 2001). This finding suggests that in-group biases on the part of permanent workers will be of a greater magnitude than the corresponding out-group biases of temporary employees. Whether this differential bias will also emerge with implicit measures is unclear, however, as implicit measures were not included in the meta-analysis. For this reason, it is hypothesized that although both temporary and permanent employees will favor permanent workers, this bias will be of greater magnitude among permanent employees, at least when measured explicitly.

Implicit measures of attitude or bias are often dissociated from explicit measures (Fazio \& Olson, 2003), particularly when social desirability is an important concern (Poehlman, Uhlmann, Greenwald, \& Banaji, 2005). Therefore, it is not necessarily the case that implicit biases will emerge in parallel to those predicted for the explicit measure. Nevertheless, the socio-structural variables reviewed above suggest that the same patterns of bias are also likely to emerge on an implicit measure of bias. Because both temporary and permanent employees view the status differential as legitimate, social desirability should not lead them to mask their feelings of bias. Consequently, temporary and permanent employees should both exhibit favoritism toward permanent employees, on implicit as well as explicit measures. Hence, while it is expected that both permanent and temporary employees will favor permanent employees on implicit and explicit bias, the two measures may not reveal the exact same pattern. As has been variously noted, correspondence and lack thereof between implicit and explicit measures can both emerge, even when they are tapping different attitude representations (e.g. Wilson, Lindsay, \& Schooler, 2001). In the current research, we expected that the overall pattern of bias should be mirrored in implicit and explicit measures, although differences between permanent and temporary employees may only manifest themselves in explicit measures. 


\section{Method}

\section{Participants and procedure}

Temporary and permanent employees from organizations throughout the Midwestern region of the United States were asked to complete a survey about their attitudes toward work and their coworkers. Participation was solicited at business association meetings for human resource managers and packets of surveys were given to 179 interested managers. Managers were asked to distribute the surveys to their employees. All survey participants were informed that their responses were confidential and that no one in the organization would have access to completed surveys. By mailing the survey directly back to the researcher, participants could be reassured of anonymity, particularly given that no record was kept of which organization received which packet, or of which employee was asked to complete a survey.

A total of 99 permanent employees completed the questionnaire. Of those completing the questionnaires there were 49 males and 46 females, and 4 who did not indicate their gender. The mean age was 37 , with the youngest employee being 21 and the oldest being 69 . The average amount of time that employees worked at their current organization was 7 years and 7 months. Likewise, a total of 62 temporary employees completed the questionnaire. There were 33 male and 29 female participants. The mean age of the temporary employees taking part was 36 years, with the youngest employee being 17 and the oldest being 64 . The average amount of time that employees worked at their current organization was 13 months, and the average amount of time that the employees had worked in a temporary capacity was 22 months. Gender, age, and tenure of the participants were unrelated to the dependent variables (all $p \mathrm{~s}>.10$ ).

\section{Measures}

Socio-structural variables To measure the socio-structural variables, temporary employees were asked to indicate their agreement or disagreement with a series of statements, to which they responded on 7-point scales with endpoints labeled disagree strongly and agree strongly. Perceptions of the relative status of temporary and permanent work were assessed by, 'I would prefer permanent work over temporary work if it were available', and 'I would rather be a permanent employee'. ${ }^{1}$ To measure perceptions of group permeability, temporary employees were asked to indicate their agreement/disagreement with the statements, 'I am working as a temporary employee in hope of finding a permanent position', and 'I think I have a good chance of getting a permanent job through a temporary assignment'. Because previous research revealed that the opposite questions (i.e. about preferring temporary work and trying to gain temporary work) would have seemed bizarre to permanent employees (C. von Hippel et al., 1997), permanent employees were simply asked, 'In your opinion, what percentage of your temporary coworkers are hoping to gain a permanent job through a temporary position?'

Explicit bias An explicit measure of in-group bias based on Tajfel's (Tajfel, Billig, Bundy, \& Flament, 1971) allocation matrices was used. The allocation matrix is a common way to assess the behavioral manifestation of in-group favoritism (Billig \& Tajfel, 1973; Tajfel et al., 1971). The general paradigm involves giving participants the opportunity to allocate money to two other people-an out-group member and an in-group member. The identity of the two people is typically indicated via labels specifying group membership. Although Tajfel used many different matrices, two choice matrices were chosen for inclusion in this study.

The two choice matrices differed slightly in that one matrix contained a midpoint that allowed for an equal distribution, while the other forced respondents to favor one group over the other. Participants were told that this section of the study was concerned with employees' perceptions of fair and equitable bonuses under a variety of circumstances. It was explained that because money is limited, bonuses cannot always be allocated equally, and sometimes not all of those who are deserving will get bonuses. Thus, under some circumstances 
they may feel that money should be shared equally, but other times equity or opportunity might suggest that money be given out disproportionately to different members of the organization. Participants were then given two hypothetical scenarios and were instructed to indicate which breakdown of the bonus they felt was most appropriate. The following is an example of the forced-choice matrix. The scale for the non-forced-choice matrix was similar, although it used a 13-point scale rather than the 14-point scale used below.

Due to the high degree of accuracy among tellers in local banks, a bonus of US $\$ 15,000$ is being distributed among them. A decision of how to allocate these funds needs to be made, as they will not necessarily be divided equally among temporary and permanent employees. Please circle the letter indicating the breakdown of this bonus that you feel is most appropriate.

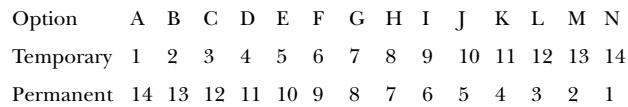

Implicit bias As was previously mentioned, an implicit measure of in-group bias was assessed via the LIB. Four scenarios were used to assess the LIB. Two scenarios presented a temporary employee as the target, and two scenarios presented a permanent employee as the target. These scenarios differed in whether the target performed well or poorly. For example, the following is a scenario in which a temporary employee is portrayed in a positive fashion.

Garrett Hunter, a temporary employee who is working in our credit department, is being commended for his outstanding performance. Garrett began working with us two months ago through a contract with one of our temporary vendors. Since that time, Garrett has successfully collected $72 \%$ of the cases that he has been given. Additionally, he has arranged a partial payment plan with another $14 \%$ of the cases. Not only has Garrett successfully collected many overdue credit card bills from customers, but he has done so with top-notch customer service.

Scenarios were counterbalanced to equate for stimulus effects such that half of the participants read about Garrett as a temporary employee, and half of the participants read about Garrett as a permanent employee.

Four descriptive statements followed each scenario. These were developed according to Semin and Fiedler's (1988) Linguistic Category Model. In accordance with this model the four statements ranged from least to most abstract, such that the first statement referred to objective descriptions of observable behaviors that have a clear beginning and end (e.g. Garrett has collected a great deal of money), and the last statement described highly abstract personal dispositions (e.g. Garrett is a good employee). Participants were asked to indicate on a 10-point scale, anchored by describes very poorly and describes very well, how well each statement described the paragraph.

Using the example presented earlier about Garrett, if participants feel that the concrete but not the abstract statement provides a good description of the scenario when Garrett is a temporary worker, then they are unwilling to communicate an inference about the positive performance of a temporary worker. In contrast, if participants feel that the abstract statement is a good description of the scenario when Garrett is a permanent employee, then they are willing to communicate an inference about the positive performance of a permanent worker. This pattern of results would indicate an implicit bias favoring permanent workers.

\section{Results}

\section{Socio-structural variables}

Consistent with expectations, temporary workers agreed with the statements that they would prefer permanent work to temporary work $(M$ $=6.02, S D=1.64)$, and that they would rather be a permanent employee $(M=5.85, S D=$ 1.89). $T$ tests revealed that both of these values were significantly different from the neutral, midpoint of the scale $(t(61)=9.65, p<.001$, $t(61)=7.73, p<.001$, respectively). Temporary employees also agreed with the statements that they were hoping to find a permanent position $(M=5.63, S D=1.98)$, and that they think they have a good chance of doing so $(M=5.50, S D$ 
$=1.56)$. Again, these values were significantly different from the neutral, midpoint of the scale $(t(61)=6.49, p<.001$ and $t(65)=7.59$, $p<.001$ respectively). These views are echoed by the permanent employees, who reported that they thought that $68 \%(S D=32 \%)$ of temporary workers are hoping to gain a permanent job. These results are consistent with previous research (e.g. C. von Hippel et al., 1997) suggesting that temporary and regular workers both perceive temporary workers as members of a low status group with permeable boundaries. $^{2}$

\section{Allocation matrices}

Employees were asked to distribute bonuses among permanent and temporary employees. The first step in the analysis was to examine whether permanent employees and temporary employees showed significant bias against their temporary coworkers. For this analysis, the response scales were recoded so that absence of bias equaled zero. Specifically, for the forcedchoice allocation matrix, 7.5 was subtracted from their score, and for the non-forced-choice allocation matrix, 7 was subtracted. This subtraction resulted in the forced-choice-scale having a range of -6.5 to 6.5 , and the nonforced-choice scale having a range of -6 to 6 , both with a centerpoint of zero. A $t$ test was then conducted on each matrix to determine whether the allocations that were chosen differed significantly from the no-bias, zero point. The $t$ test for the forced-choice allocation matrix revealed that allocations made by both permanent and temporary workers differed significantly from zero $(t(88)=-12.52, p<.001$, $t(57)=-5.54, p<.001$, respectively). The $t$ test for the non-forced-choice allocation matrix also revealed that allocations made by both permanent and temporary workers differed significantly from zero $(t(87)=-10.62, p<.001, t(59)$ $=-2.65, p<.01$, respectively). Thus, as predicted both permanent and temporary workers favored permanent employees.

The next step in the analysis was to assess whether the permanent employees showed more bias against temporary employees than the temporary employees did. Consistent with this possibility, an analysis of variance (ANOVA) on the results of the forced-choice allocation matrix revealed that permanent workers were more biased against temporary workers $(M=$ -2.86) than were their temporary counterparts $(M=-1.71)(F(1,145)=46.66, p<.01)$. The ANOVA for the non-forced-choice allocation matrix also revealed that permanent workers were more biased $(M=-2.77)$ against temporary workers than were their temporary counterparts $(M=-.89)(F(1,146)=20.31, p<.001)$.

\section{LIB}

The next step in the analysis was to assess whether the explicit bias that emerged against temporary employees was reflected in the measure of implicit bias. In order to assess implicit bias, participants' language abstraction was examined with a 2 (participant's group membership: temporary vs. permanent employee) $\times 2$ (target employee type: temporary vs. permanent employee) $\times 2$ (favorability of behavior: positive vs. negative) $\times 4$ (language abstraction level) mixed-model ANOVA with repeated measures on the last three variables. According to predictions, a three-way interaction should emerge between a protagonist's group membership, favorability of their behavior, and their language abstraction level, such that people should prefer abstract descriptions when temporary employees engage in a negative behavior or permanent employees engage in a positive behavior and concrete descriptions when temporary employees engage in a positive behavior or permanent employees engage in a negative behavior. This pattern of findings would suggest that participants have an implicit bias against temporary employees. Furthermore, if an equivalent level of implicit bias emerges among temporary and permanent employees, this predicted three-way interaction should not itself be moderated by the participant's group membership. That is, the presence of this three-way interaction in the absence of a four-way interaction would indicate that temporary and permanent employees are showing equivalent bias on the LIB.

Consistent with these possibilities, analyses failed to reveal a four-way interaction $(F(3,477)$ 
$=0.47, p=0.70)$, but did reveal the predicted three-way interaction between target employee type, story valence, and abstraction level $(F(3,477)=4.62, p<.01)$. To decompose this three-way interaction, separate analyses of variance were conducted at each level of abstraction. These analyses revealed the predicted and opposite interactions between target employee type and story valence for the most concrete descriptors $(F(1,159)=4.55, p<.05)$ and the most abstract descriptors $(F(1,159)=$ $4.98, p<.05$ ), (see Figure 1). As is often the case with the intermediary descriptors (e.g. see W. von Hippel et al., 1997), analyses revealed no interactions with the moderately concrete $(F(1,159)=2.76, p<.10)$ or moderately abstract $(F(1,159)=2.57, p>.10)$ descriptors.

Consistent with the absence of the four-way interaction, none of the simple effects analyses revealed any moderating effect of responding employee type on the interaction between target employee type and story valence $\left(F_{\mathrm{s}}<1\right.$, $p \mathrm{~s}>.40)$. Thus, these findings indicate that the LIB did not differ by responding employee type, suggesting that in contrast to the measure of explicit bias, permanent and temporary employees were showing the same degree of bias in the LIB task. Main effects also emerged for level of abstraction $(F(3,477)=38.19, p<$ $.01)$ and valence $(F(1,159)=57.31, p<.01)$, and an interaction emerged between abstraction and valence $(F(3,477)=144.12, p<.01)$. These effects are stimulus effects, and no other main effects or interactions emerged.

To summarize, both temporary and permanent employees preferred the more abstract statements when evaluating the positive scenarios, although this preference was greater when reading about a permanent employee who engaged in positive behavior than a temporary

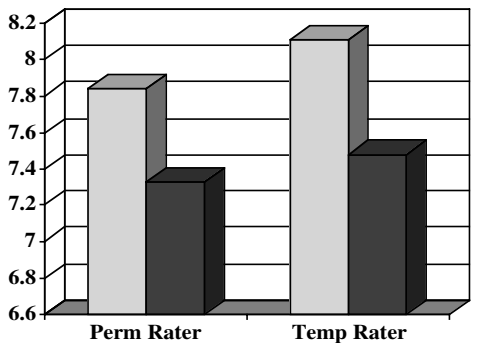

Ratings of Positive Behaviors Concrete Descriptors

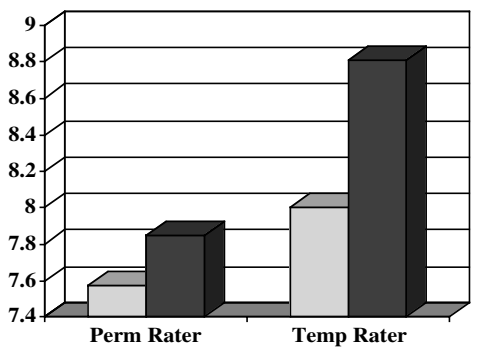

Ratings of Positive Behaviors Abstract Descriptors

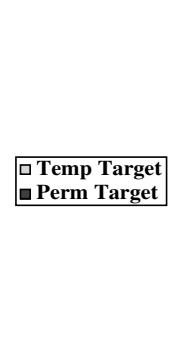

口 Temp Target $\square$ Perm Target

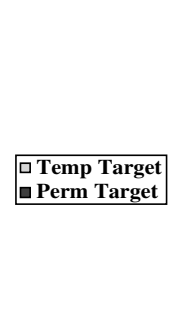

5.6
5.4
5.2
5
4.8
4.6
4.4
4.2
4

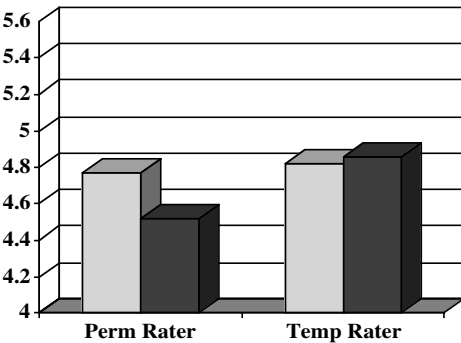

Ratings of Negative Behaviors Abstract Descriptors

Figure 1. Level of preference for the concrete and abstract descriptors by responding employee type for permanent and temporary employees' positive and negative behavior. 
employee who engaged in the same positive behavior. The opposite pattern emerged with the negative scenarios. Temporary and permanent employees preferred the more concrete statements when evaluating the negative scenarios, although this preference was greater when reading about a permanent employee who did something negative.

The pattern of results among permanent employees is consistent with previous research on the LIB by Maass and her colleagues (1989, 1995), and extends that research to the domain of intergroup relations in the workplace. The pattern of results with temporary employees, in contrast, is the first evidence of an out-group bias using the LIB. This pattern of results suggests that positive behaviors are more expected of permanent employees, and thus both temporary and permanent employees are more willing to abstract from a permanent employee's good performance than a temporary employee's good performance. Negative behaviors, in contrast, are more expected of temporary employees, and thus both temporary and permanent employees are more willing to abstract when a temporary employee does something negative than when a permanent employee does something negative.

The final goal of the analyses was to assess the relationship between the measures of explicit and implicit intergroup bias separately for temporary and permanent employees. To create a measure of explicit bias, responses to the two allocation matrices were averaged together. Likewise, to create a measure of implicit bias, participants' ratings of the abstract description of a positive temporary employee were subtracted from their ratings of the abstract description of a positive permanent employee. The same procedure was then conducted in reverse for the negative behavior, and these difference scores were added together, with the resultant measure providing an indication of how much participants preferred the abstract description when it favors the permanent over the temporary employee (see W. von Hippel et al., 1997). With this coding, a negative correlation between the two measures would indicate that employees who show bias against temporary employees on the implicit measure also show bias against temporary employees on the explicit measure. The correlation between the implicit and explicit measures of intergroup bias was significant for temporary employees $(r=-.28, p<.04)$ but not for permanent employees $(r=.14, p>.15)$.

\section{Discussion}

SIT suggests that members of low status groups who have the potential to gain entrée to a higher status group should show out-group favoritism. The current article examined this possibility among naturally occurring groups with permeable boundaries. Results revealed out-group favoritism on the part of the lower status temporary employee group on both the implicit and explicit measures. In contrast, the higher status permanent employee group displayed typical in-group favoritism on both measures. Although social identities typically provide a positive sense of self, the current results confirm Tajfel's (1978) prediction that when a group is low status but has permeable boundaries, members may denigrate their own group as part of an ongoing effort to change group membership. This finding suggests that members of low status, permeable groups are unlikely to be highly identified with their group membership, and instead will typically deal with the problem of a poor social identity by trying to change group membership.

Although SIT postulates that there are a number of moderators concerning when ingroup enhancement versus out-group favoritism will emerge, population specific moderators may emerge as well. With regard to temporary employees, previous research suggests that there may be two types of temporary employees: voluntary and involuntary (e.g. C. von Hippel, Greenberger, Mangum, \& Heneman, 2000). Voluntary temporary employees are working in this capacity by choice, perhaps because of the flexibility or variety temporary work has to offer. Involuntary temporary employees, in contrast, are hoping to gain a permanent job through their temporary placement. This classification suggests that the current research 
findings might be moderated by the type of temporary employee. Voluntary temporary employees may show typical in-group favoritism, as permeable group boundaries are unimportant to this type of temporary worker because they prefer their current social categorization as a temporary employee. Involuntary temporary employees may be the only ones who show out-group favoritism, because they are desirous of membership in the higher status group. Such a possibility that the temporary employee type might moderate these findings would provide further support for the role of sociostructural variables posited by SIT.

It is worth noting that although there were no differences between members of the low and high status groups in the degree of bias shown on the implicit measure, the explicit measure revealed greater bias on the part of the high status group. The presence of greater bias on the explicit, but not the implicit, measure is opposite to what is typically found in research on intergroup relations, with implicit bias in the absence of explicit bias being the norm (e.g. Franco \& Maass, 1996). One can only speculate as to why this finding emerged, but the fact that the correlation between the two types of measures was reliable for temporary but not permanent employees suggests that permanent employees may have been strategically altering their responses on the allocation matrices. If so, given that permanent employees showed more bias than temporary employees on the allocation matrices, this finding suggests that permanent employees may have actually exaggerated the degree of bias that they felt against temporary employees. Thus, it seems possible that in this situation the norm is to report greater intergroup discrimination than one truly feels. The possibility of such a norm suggests that relationships between temporary and permanent employees might be marked by pluralistic ignorance, in which permanent employees believe that other permanent employees are more negative about temporary employees than they really are. Given that such cases of pluralistic ignorance can bring about their own reality (Prentice \& Miller, 1993), this finding suggests yet another source of potential strain between permanent and temporary workers.

\section{Implications and limitations}

The current results provide a real-world example of Jost and Banaji's (1994) system justification theory, which argues that low status group members may justify the existing social system by blaming fellow group members, rather than fighting for equality. If people justify the current status hierarchy, then biases against lower status groups in the workplace will not meet with resistance. One of the factors that maintain equity in the competitive environment of the workplace is that members of most groups attempt to act in their own, and in their group's, best interest. If members of certain low status groups show a bias in favor of members of other groups, then such groups are likely to remain relatively disadvantaged, as no one is likely to act or speak on their behalf. Such a situation where low status groups favor the high status group will make it even more difficult for lower status groups to improve their group's position, as members of these groups may be unlikely to defend each other, unlikely to unionize, etc. Thus, an important implication of the current results is that low-status, permeable groups may be more likely to remain disadvantaged, and less likely to have spokespersons act on their behalf, than groups that are equally low in status but have impermeable boundaries.

The linguistic patterns that participants demonstrated suggest an additional disadvantage for temporary employees in the workplace. With the host of biases that perpetuate stereotypes and discrimination in the workplace (e.g. hypothesis confirming bias, expectancy confirmation), the current data suggests that linguistic styles may also be of concern. Both permanent and temporary employees preferred to describe negative behaviors by temporary employees in abstract terms, but positive behaviors by temporary employees in concrete terms. This linguistic style not only demonstrates the implicit expectancies of those who display it, but it also leads to perpetuation of the expectancies in those who hear these 
descriptions (Wigboldus et al., 2000). Because people are more likely to make dispositional inferences when they hear behaviors described abstractly, the LIB causes listeners to make dispositional inferences in a biased fashion. Thus, even if temporary and permanent workers perform identically on the job, if their coworkers show the LIB in describing those behaviors, others will form the impression that the temporary employees have not performed as well as the permanent employees. In this way, stereotypes about temporary employees may be perpetuated through subtle differences in language abstraction. The current data suggests that temporary employees are unlikely to receive credit when they succeed, but will be blamed when they fail.

Finally, to round things off, there are some limitations with this study that are worth noting. First, the explicit measure of bias may have itself been biased in the direction of permanent employees. For example, if employees adopted a strategy of how to allocate bonuses based on the perceived length of time the different groups have been at the organization, then temporary employees would necessarily be disadvantaged. With regard to this concern, however, it should be noted that the average tenure of temporary employees at the current organization was over a year. Furthermore, the fact that bias was found on the implicit measure indicates that temporary employees are indeed favoring the out-group.

A second concern deals with the potential selection effects that may have influenced the findings of this research. Only one temporary employee was chosen to participate by each supervisor. It is possible that the temporary employees chosen by the various supervisors differed from the general population of temporary employees in some systematic way. For example, these temporary employees may have been at the organization longer, and been more serious than those temporary employees who were not chosen for inclusion in this study. Alternatively, it is also possible that supervisors simply distributed surveys to employees who were 'in the right place at the right time'. This limitation is also a possible strength of the study, however. Because data were collected from multiple organizations in multiple industries (from public and private sector, service and manufacturing), the results have greater potential to generalize across varied samples of workers.

\section{Notes}

1. The labels 'permanent employee' and 'permanent work' are common terms in the jargon of temporary workers to refer to regular, full-time employment. These terms do not insinuate that the worker would have lifetime guaranteed employment.

2. Perceptions of permeability and status differences were also assessed among an independent sample of temporary $(n=41)$ and permanent employees $(n=80)$ working in Australia. Permeability was assessed with the item, 'Many temporary employees gain permanent jobs through their temporary placements' and status was assessed with the item, 'In general, permanent employees have a higher status compared to temporary employees'. Respondents indicated their agreement with these items using a 7-point scale anchored by strongly disagree and strongly agree. Results revealed that temporary employees were perceived as lower status $(M=5.80, S D=1.21$ for the combined sample; $M=5.31, S D=1.08$ for the temporary employee sample) and the boundaries were perceived as permeable $(M=5.12, S D=1.35$ for the combined sample; $M=5.83, S D=1.32$ for the temporary employee sample). All of these means were significantly different from the scale midpoint, $t \mathrm{~s}>9.0, p \mathrm{~s}<.001$.

\section{Acknowledgments}

Thanks to William von Hippel, Elizabeth George and Raja Chattopadhyay for helpful comments on an earlier draft of the manuscript.

\section{References}

Allerton, H. (1996). News you can use. Training $\mathcal{E}$ Development, 50, 9-12.

Bettencourt, B. A., Dorr, N., Charlton, K., \& Hume, D. L. (2001). Status differences and in-group bias: A meta-analytic examination of the effects of status stability, status legitimacy, and group permeability. Psychological Bulletin, 127, 520-542. 
Bem, S. L. (1994). The lenses of gender. New Haven, CT: Yale University Press.

Billig, M., \& Tajfel, H. (1973). Social categorization and similarity in intergroup behavior. European Journal of Social Psychology, 3, 27-52.

Boldry, J., \& Kashy, D. (1999). Intergroup perception in naturally occurring groups of differential status: A social relations perspective. Journal of Personality and Social Psychology, 77, 1200-1212.

Boroughs, D. L. (1994). The new migrant workers: Part time and temporary job holders toil for low pay and limited benefits. US News Eं World Report, July 4.

Bourhis, A., \& Wils, T. (2001). The fragmentation of traditional employment: Challenges raised by the diversity of typical and atypical jobs. Industrial Relations, 56, 66-91.

Brewer, M. B. (1979). In-group bias in the minimal group situation: A cognitive-motivational analysis. Psychological Bulletin, 86, 307-324.

Brewer, M. B., \& Brown, R. J. (1998). Intergroup relations. In D. T. Gilbert \& S. T. Fiske (Eds.), The handbook of social psychology (pp. 554-594). New York: McGraw-Hill.

Chattopadhyay, P., \& George, E. (2001). Examining the effects of work externalization through the lens of social identity theory. Journal of Applied Psychology, 86, 781-788.

Davidson, L. (1999). Temp workers want a better deal. Workforce, 78, 44.

Davis-Blake, A., \& Uzzi, B. (1993). Determinants of employment externalization: A study of temporary workers and independent contractors.

Administrative Science Quarterly, 38, 195-223.

Ellemers, N., van Knippenberg, A., de Vries, N., \& Wilke, H. (1988). Social identification and permeability of group boundaries. European Journal of Social Psychology, 18, 497-513.

Ellemers, N., van Knippenberg, A., \& Wilke, H. (1990). The influence of permeability of group boundaries and stability of group status on strategies of individual mobility and social change. British Journal of Social Psychology, 29, 233-246.

Fazio, R. H., \& Olson, M. A. (2003). Implicit measures in social cognition research: Their meaning and use. Annual Review of Psychology, 54, 297-327.

Feldman, D. C., Doerpinghaus, H. I., \& Turnley, W. H. (1994). Managing temporary workers: A permanent HRM challenge. Organizational Dynamics, Autumn, 49-63.

Feldman, D. C., Doerpinghaus, H. I., \& Turnley, W. H. (1995). Employee reactions to temporary work. Journal of Managerial Issues, 7, 127-141.
Franco, F. M., \& Maass, A. (1996). Implicit versus explicit strategies of out-group discrimination: The role of intentional control in biased language use and reward allocation. Journal of Language $\mathcal{E}^{\circ}$ Social Psychology, 15, 335-359.

Jost, J. T., \& Banaji, M. R. (1994). The role of stereotyping in system justification and the production of false consciousness. British Journal of Social Psychology, 33, 1-27.

Jost, J. T., Banaji, M. R., \& Nosek, B. A. (2004). A decade of system justification theory: Accumulated evidence of conscious and unconscious bolstering of the status quo. Political Psychology, 25, 881-919.

Lindeman, M., \& Sundvik, L. (1995). Evaluative bias and self-enhancement among gender groups. European Journal of Social Psychology, 25, 269-280.

Maass, A., Milesi, A., Zabbini, S., \& Stahlberg, D. (1995). Linguistic intergroup bias: Differential expectancies or in-group protection? Journal of Personality and Social Psychology, 68, 116-126.

Maass, A., Salvi, D., Arcuri, L., \& Semin, G. (1989). Language use in intergroup contexts: The linguistic intergroup bias. Journal of Personality and Social Psychology, 57, 981-993.

Mummendey, A., Simon, B., Dietze, C., Grunert, M., Haeger, G., Kessler, S. et al. (1992). Categorization is not enough: Intergroup discrimination in negative outcome allocation. Journal of Experimental Social Psychology, 28, 125-144.

Otten, S., Mummendey, A., \& Blanz, M. (1996). Intergroup discrimination in positive and negative outcome allocations: Impact of stimulus valence, relative group status, and relative group size. Personality and Social Psychology Bulletin, 22, 568-581.

Poehlman, T. A., Uhlmann, E., Greenwald, A. G., \& Banaji, M. R. Understanding and using the Implicit Association Test: III. Meta-analysis of predictive validity. Unpublished manuscript.

Prentice, D. A., \& Miller, D. T. (1993). Pluralistic ignorance and alcohol use on campus: Some consequences of misperceiving the social norm. Journal of Personality and Social Psychology, 64, 243-256.

Rogers, J. K. (1995). Just a temp: Experience and structure of alienation in temporary clerical employment. Work and Occupation, 22, 137-166.

Sachdev, I., \& Bourhis, R. (1987). Status differentials and intergroup behaviour. European Journal of Social Psychology, 17, 277-293.

Sekaquaptewa, D., \& Espinoza, P. (2004). Biased processing of stereotype-incongruency is greater for low than high status groups. Journal of Experimental Social Psychology, 40, 128-135. 
Semin, G. R., \& Fiedler, K. (1988). The cognitive functions of linguistic categories in describing persons: Social cognition and language. Journal of Personality and Social Psychology, 54, 558-568.

Stewart, T. L., Vassar, P. M., Sanchez, D. T., \& Susannah, E. (2000). Attitude toward women's societal roles moderates the effect of gender cues on target individuation. Journal of Personality and Social Psychology, 79, 143-157.

Tajfel, H. (1978). Differentiation between social groups: Studies in the social psychology of intergroup relations. London: Academic Press.

Tajfel, H. (1982). Social identity and intergroup relations. Cambridge, MA: Cambridge University Press.

Tajfel, H., Billig, M., Bundy, R., \& Flament, C. (1971). Social categorization and intergroup behavior. European Journal of Social Psychology, 1, 149-178.

Tajfel, H., \& Turner, J. C. (1979). An integrative theory of intergroup conflict. In S. Worchel \& W. G. Austin (Eds.), The social psychology of intergroup relations (pp. 33-47). Monterey, CA: Brooks/Cole.

Tajfel, H., \& Turner, J. C. (1986). The social identity theory of intergroup behavior. In S. Worchel \& W. G. Austin (Eds.), Psychology of intergroup relations (pp. 7-24). Chicago: Nelson-Hall.

Turner, J. C., \& Brown, R. (1978). Social status, cognitive alternatives, and intergroup relations. In H. Tajfel (Ed.), Differentiation between social groups: Studies in the social psychology of intergroup relations (pp. 201-250). London: Academic Press.

Tyler, K. (2004). Making the transition. HR Magazine, 49, 97-102.

von Hippel, C., Greenberger, D. B., Mangum, S. L., \& Heneman, R. (2000). Voluntary and involuntary temporary employees: Predicting satisfaction, commitment, and personal control. In R. Hodson (Ed.), Research in the sociology of work, 8. Greenwich, CT: JAI Press.

von Hippel, C., Mangum, S. L., Greenberger, D. B., Heneman, R. L., \& Skoglind, J. D. (1997).

Temporary employment: Can organizations and employees both win? The Academy of Management Executive, 11, 93-104.

von Hippel, W., Sekaquaptewa, D., \& Vargas, P. (1997). The Linguistic Intergroup Bias as an implicit indicator of prejudice. Journal of Experimental Social Psychology, 33, 490-509.

Wheeler, A. R., \& Buckley, R. M. (2001). Examining the motivation process of temporary employees: a holistic model and research framework. Journal of Managerial Psychology, 16, 339-354.

Wigboldus, D. H., Semin, G. R., \& Spears, R. (2000). How do we communicate stereotypes? Linguistic bases and inferential consequences. Journal of Personality and Social Psychology, 78, 5-18.

Wilson, T. D., Lindsay, S., \& Schooler, T. Y. (2001). A model of dual attitudes. Psychological Review, 107, 101-126.

Paper received 1 June 2005; revised version accepted 28 February 2006.

\section{Biographical note}

COURTNEY D. VON HIPPEL is a lecturer in psychology at The University of New South Wales, Sydney, Australia. Her research focuses on intergroup relations in the workplace, examining blended workforces as well as focusing on women in leadership. 